\title{
Contribution of a Websig to a Study of the Distribution of Education Staff for Vocational Training in Côte D'ivoire
}

\author{
Gba Noune Elisee, Saley Mahaman Bachir, Kouassi Kan Desire \\ UFR STRM/CURAT, Félix Houphouët Boigny University, Abidjan, Côte d'Ivoire \\ Email: gbanoune@yahoo.fr
}

How to cite this paper: Elisee, G.N., Bachir, S.M. and Desire, K.K. (2021) Contribution of a Websig to a Study of the Distribution of Education Staff for Vocational Training in Côte D'ivoire. Intelligent Information Management, 13, 141-155. https://doi.org/10.4236/iim.2021.132007

Received: January 26, 2021

Accepted: March 8, 2021

Published: March 11, 2021

Copyright $\odot 2021$ by author(s) and Scientific Research Publishing Inc. This work is licensed under the Creative Commons Attribution International License (CC BY 4.0).

http://creativecommons.org/licenses/by/4.0/

\begin{abstract}
Education makes it possible to pass from one generation to another, the culture necessary for the development of the personality and the social integration of the individual. Education contributes closely to the supervision of students and remains the responsibility of educators and education inspectors. But each education staff admits the number of students supported. This number is two hundred and eighty (280) students per educator and one thousand two thousand (2000) per education inspector. Our study aims at taking stock of the adequacy between school enrollment and education staff enrollment from a WebSIG for vocational training schools in Côte d'Ivoire. To achieve this, the methodology adopted led us to use the MERISE analysis method for setting up the database, web programming languages (HTML 5, PHP, CSS, XML and JavaScript), AJAX technology, Apache web server, DBMS (MySQL), Google Maps API. The results from the use of WebSIG highlight the disparity in the distribution of education personnel. These results also show which schools remain in need as well as in excess.
\end{abstract}

\section{Keywords}

WebSIG, Cartography, MERISE, MySQL, Vocational Training Schools, Côte d'Ivoire

\section{Introduction}

Education, according to the Atheism Digital Dictionary, is the action of developing a set of knowledge and moral, physical, intellectual and scientific values, as essential to achieve the desired level of culture. Education makes it possible to transmit from one generation to another the culture necessary for the development of the personality and the social integration of the individual. It is the basis 
of development for a state insofar as it gives young people useful knowledge for their integration into working life. According to (UNESCO, 2011) [1], more than 1.5 billion children and young people are enrolled in kindergartens, primary and secondary schools and universities.

Vocational training is the learning process that allows an individual to acquire the knowledge and know-how (skill and competence) necessary for the exercise of a trade or a professional activity. It leads directly to employment and the education provided to students for integration into the world of work. This integration into the world of work can be perfect when training is combined with a good education of the learners. This is how the Ivorian state, aware of the need for this association, invests in the training of educators and education inspectors who are assigned to schools following their passage through the Ecole Normale Supérieure (ENS) of Abidjan. These assignments should be made according to an adequacy between the staffing in the schools and the number of educators on the one hand and on the other hand between the staff and the number of education inspectors. Indeed, according to the Vocational Training Department, the standard requires two hundred and eighty (280) students per educator and two thousand (2000) students per education inspector, or one education inspector for about seven (07) educators. The distribution of education staff should therefore be in line with this standard in schools in order to ensure better learning.

The objective of this work is to make an inventory from the realization of a Geographic Information System on the Internet (WebSIG) on the adequacy between the school enrollments of the schools and the number of supervisory staff in each school and nationally in the field of vocational training in Côte d'Ivoire.

\section{Study Framework}

\subsection{Geographical Location and Administrative Division}

The Côte d'Ivoire is a country located in West Africa, in the northern hemisphere between the Tropic of Cancer and the Equator, between $10^{\circ}$ and $4^{\circ}$ north latitude and $10^{\circ}$ and $0^{\circ}$ west longitude. It has an area of $322,462 \mathrm{~km}^{2}$ including $318,002 \mathrm{~km}^{2}$ of land and $4460 \mathrm{~km}^{2}$ of seas. Its economic capital is Abidjan located in the south-east of Côte d'Ivoire. Its political and administrative capital has been Yamoussoukro since March 1983, a city located in the center of the country in the Lakes Region, $248 \mathrm{~km}$ from Abidjan.

Côte d'Ivoire, since the decree $n^{\circ}$ 2011-263 of September 28, 2011 on the organization of the national territory into Districts and Regions, has fourteen (14) districts including two (2) autonomous districts which are the district of Abidjan and Yamoussoukro and thirty administrative regions. It comprises, at the end of this same decree, fourteen (14) districts (Figure 1).

\subsection{Ivorian Population}

The current population of Côte d'Ivoire is the result of historical factors (migrations of different peoples) and economic factors which have partly generated the 


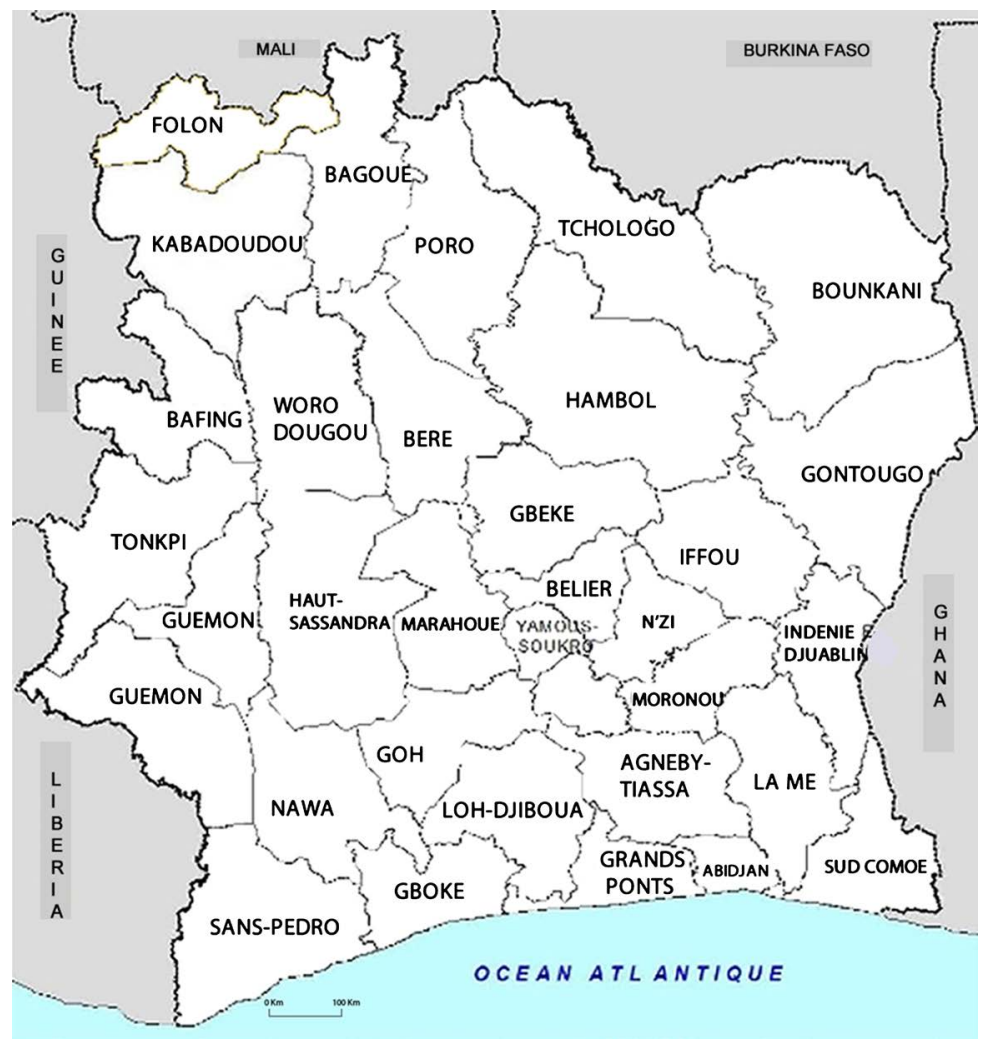

Figure 1. Map of the administrative division of Côte d'Ivoire (INS, 2015) [2].

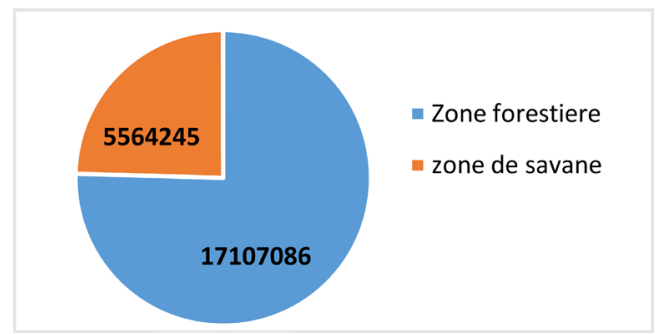

Figure 2. Population of Côte d'Ivoire by area in 2014 (RGPH, 2014) [6].

accelerated rate of demographic growth in the country and the spatial distribution of the population (Koffi, 1990) [3]. This indicates that the reasons for the population growth are mainly due to immigration inspired by the economic strengths of the country. This population was seven hundred and nine thousand $(709,000)$ inhabitants in 1975 . It rose to 10.8 million in 1988 with an average annual growth rate of $3.7 \%$ between 1975 and 1988. But the migration of populations from the neighboring countries towards Côte d'Ivoire has been held back by the various socio-political crises it has experienced since 1990 (Boutillier, 1971) [4]. These crises have also increased urban populations (Zah, 2015) [5].

Internal migration is guided by the distribution of the country's economic assets. The population is unevenly distributed over the territory as a result. It is more concentrated in forest areas (Figure 2) and in urban areas. Forest areas favor agricultural crops such as coffee, cocoa and rubber. They have always at- 
tracted the populations of the north and the center where we find grassy and tree savannah respectively.

Like the very young African population (UNICEF, 2015) [7] Côte d'Ivoire has a predominantly young population. These young people demand professional training from the state for their integration into social life. This requires good education in technical education and vocational training institutions.

\subsection{Overview on the Vocational Training in Côte d'Ivoire}

Technical education and vocational training in the Côte d'Ivoire, it is aimed at adolescents and adults between 15 and 27 years old. Vocational training is part of the education of young people and occupies a field of research and development in its own right in the sciences of education.

The technical education and vocational training system has 179 training courses with a total workforce of 105,353 (METFP, 2016) [8].

\section{Materials and Methods}

\subsection{Materials}

\subsubsection{IT Tools}

We use in this work, the Method of Study and Computer Realization for Enterprise Systems (MERISE) for the realization of the database. For the programming of web pages we use the Hyper Text Markup Language (HTML), the Extensible Markup Language (XML), the Hypertext Preprocessor (PHP), the Cascading Style Sheets (CSS), the JavaScript, the Asynchronous JavaScript And XML (AJAX) technology ), the Structured Query Language (SQL) for handling the database.

We opt for the use of the Google Maps Application Programming Interface (API) which is a standardized set of classes, methods, functions and constants which serves as a facade through which Google Maps allows other applications to realize and to distribute its own maps on the internet. We use the MySQL Database Management System for hosting the database and an Apache web server for uploading the website.

\subsubsection{Data Used}

The accomplishment of this work required for each school the number of learners, the number of educators and education inspectors and the geographical coordinates of the schools. The chosen school year is 2018-2019. This choice is justified by the availability of consolidated data for this year, both in terms of the number of learners and supervisors.

\subsection{Methods of Drawing up the School Map According to the Number of Education Staff}

\section{Step 1: Creation of the database}

\section{1) Management rules}

Rule 1: a school has one and only one category while a category can have zero 
(0) or more school;

Rule 2: a school depends on one and only one regional directorate while a regional directorate may depend on zero (0) or more schools;

Rule 3: a school registers one or more staff while a staff is registered for one and only one school;

Rule 4: the staff concerns one and only one year while a year may be concerned with zero (0) or more staff;

Rule 5: the staff belongs to one and only one type while a type can belong to zero (0) or more number of students or staff.

\section{2) Data dictionary}

A data dictionary is a collection of data of different types recorded in a table for setting up a relational database.

Table 1 is the data dictionary resulting from the collection of information in the various departments and establishments of Technical Education and Vocational Training.

\section{3) Conceptual Data Model}

The Conceptual Data Model resulting from this analysis is represented by Figure 3.

\section{4) Physical data model}

The Physical Data Model (PDM) step is to implement the logical model in the DBMS. To do this, we develop the Figures (Table 2, Table 3, Table 4, Table 5 and Table 6) which present the characteristics of each of the figures of the Physical data model.

\section{Step 2: Methology of the education staff entry}

We enter the number of educators and educational inspectors of schools for a school year through an interface represented by Figure 4 . The interface also allows

Table 1. Data dictionary.

\begin{tabular}{cccc}
\hline codification & Description & Type & Length \\
\hline Id_chool cate & School category ID & N & 5 \\
School_category_label & School category label & AN & 2 \\
School_id & School ID & AN & 4 \\
School_label & School label & AN & 40 \\
Staff_id & Staff ID & AN & 10 \\
staff & Staff & AN & 30 \\
Staff_type_id & Staff type id & AN & 6 \\
Staff_type_label & Name of the type of workforce & AN & 30 \\
id_dr & Identifier of the regional office & N & 3 \\
Dr_label & Wording of the regional office & AN & 40 \\
School_year_id & School year id & N & 3 \\
School_year_label & Name of the school year & AN & 15 \\
\hline
\end{tabular}




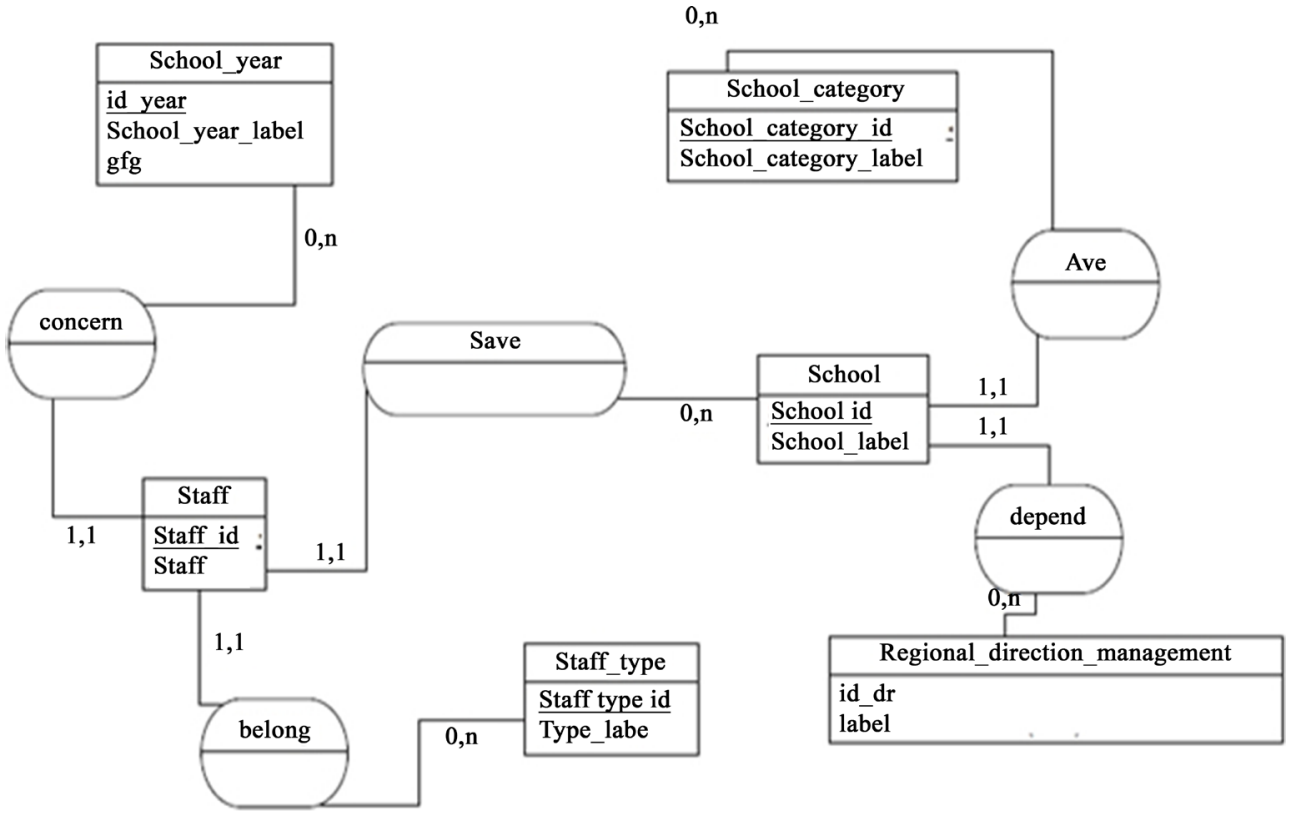

Figure 3. Conceptual data model.

Table 2. School_category.

\begin{tabular}{cccc}
\hline codification & Description & Type & Length \\
\hline School_category_id & School category id & N & 2 \\
School_category_label & School category label & AN & 50 \\
\hline
\end{tabular}

Table 3. t_school.

\begin{tabular}{cccc}
\hline codification & Description & Type & Length \\
\hline School_id & School ID & Integer & 2 \\
School_label & School label & Char & 35 \\
\#School_category_id & School category id & Integer & 2 \\
\#Dir_id & Direction id & Integer & 3 \\
\hline
\end{tabular}

Table 4. t_school_year.

\begin{tabular}{cccc}
\hline Codification & Description & Type & Length \\
\hline School yea id & School year ID & Integer & 3 \\
School year label & school year label & caractère & 16 \\
\hline
\end{tabular}

Table 5. t_staff.

\begin{tabular}{cccc}
\hline Codification & Description & Type & Length \\
\hline Staff_id & Staff ID & Entier & 3 \\
Staff & Staff & Entier & 16 \\
\#School_ & School ID & Entier & 2 \\
\#Staff_type_id & Staff type ID & Entier & 6 \\
\#School_year_ID & School year ID & Entier & 3 \\
\hline
\end{tabular}


Table 6.t_regional_management_direction.

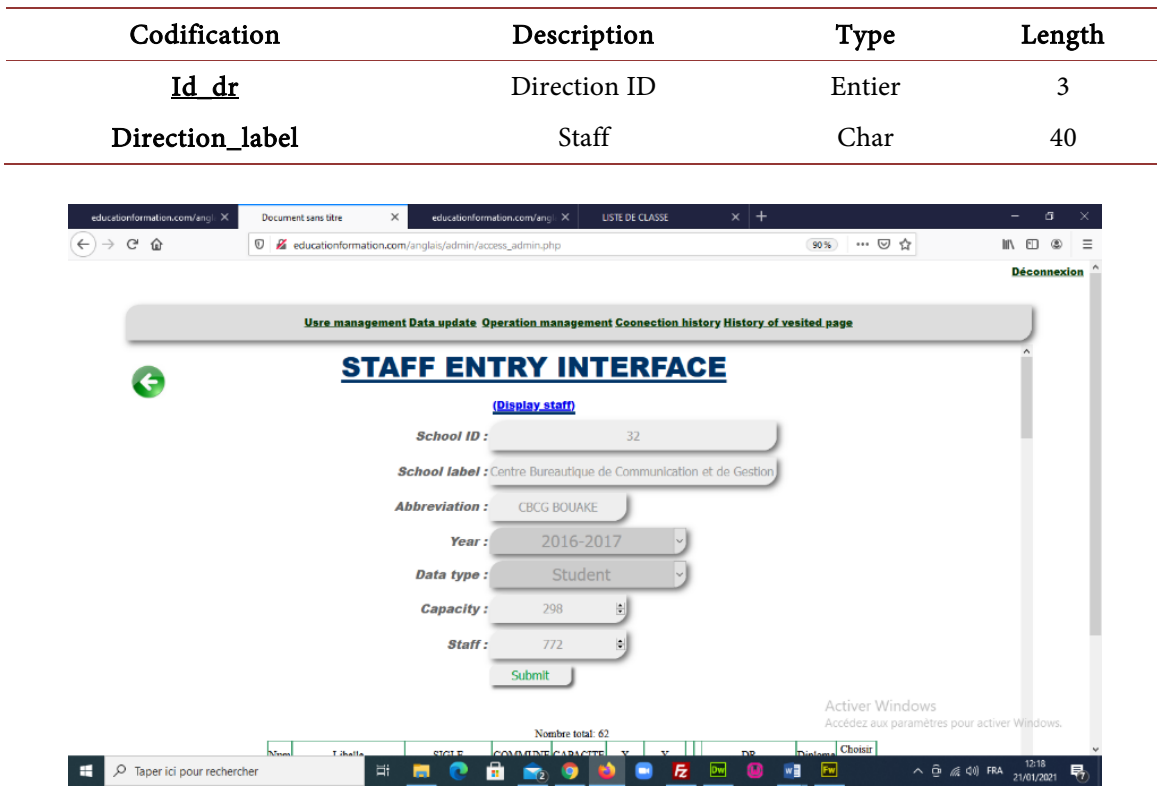

Figure 4. Staff entry interface.

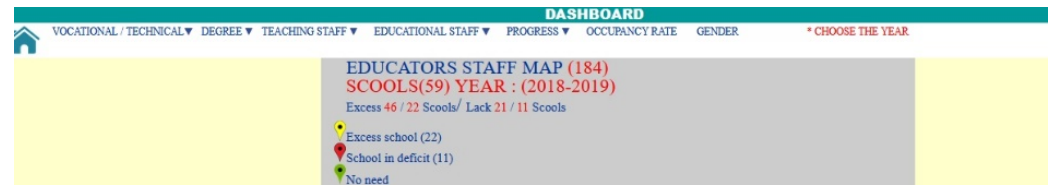

Figure 5. General interface for editing maps.

entering the number of students by school.

\section{Step 3: Customization of markers for educators}

We create a web interface for presenting maps

(http://www.educationformation.com/anglais/tableaudebord/). This map display interface offers a menu that displays the type of map to edit (Figure 5).

When the "supervisory staff" option is chosen, the system sends a request which extracts the number of educators from each school (Request 1).

Request 1: Selection request for the number of educators by school.

\$req_diplome="SELECT ${ }^{*}$ FROM t_ecole, t_effectif WHERE

t_ecole.id_ecole=t_effectif.id_ecole AND t_effectif.id_type_donnee ='\$num' AND

t_effectif.annee='\$annee' AND pays.id_pays='1' AND ministere.id_ministere='1' ";

A second Request selects the school numbers of each school (Query 2).

Request 2: School enrollment selection request by school.

\$req2="SELECT * FROM t_effectif WHERE

t_effectif.id_ecole='\$id_ecole' AND annee='\$annee' AND id_type_donnee='3000' ";

Each school population is divided by two hundred and eighty (280) to con- 
form to the standard. The quotient of this operation is compared to the number of educators that came out of the database by the first query 1 . The criteria for assigning colors are:

- When the number of educators is greater than the quotient, the marker takes on a yellow color which expresses a surplus;

- When the number of educators is less than the quotient, the marker representing the school concerned on the map takes on a red color which indicates an insufficiency;

- When the number of educators is equal to the quotient, the marker that represents the school concerned on the map takes on a green color which expresses the ideal case where there is no deficit or surplus.

\section{Step 4: Customize markers for education inspectors}

When the option of education inspectors is chosen on the card editing interface, the system sends a request (Request 3 ) to retrieve the schools with the number of inspectors for the school year in question.

Request 3: Selection request for the number of education inspectors by school.

\$req_diplome="SELECT ${ }^{*}$ FROM t_ecole, t_effectif WHERE

t_ecole.id_ecole=t_effectif.id_ecole AND t_effectif.id_type_donnee ='\$num' AND

t_effectif.annee='\$annee' AND pays.id_pays='1' AND ministere.id_ministere='1' ";

Each workforce is divided by two thousand (2000) according to the standard. The quotient of this operation is compared to the number of inspectors drawn from the database for each school. The color allocation criteria are:

- When the number of inspectors is greater than the quotient, the marker turns yellow, indicating an excess;

- When the number of inspectors is lower than the quotient, the marker turns red, indicating an insufficiency;

- When the number of inspectors is equal to the quotient, the marker turns green which expresses the ideal case where there is no deficit or surplus.

\section{Step 5 Generating the XML file for editing the maps}

The card retrieves the data extracted by SQL queries via an XML file. This program does not translate directly into HTML because there are incompatibilities between certain HTML tags and XML. Figure 6 shows an extract of the XML file generated to transmit the data stored in the database to the card when certain characteristics of the schools are targeted by the requests.

\section{Step 6: Display of the map of the XML file}

The display of the map from the XML file requires several files, the two main ones being the HTML 5 file and the PHP file which include a JAVASCRIPT code. The HTML5 file includes the CSS files that take care of the interface layout. It specifies the Google Maps API key obtained after registering our project on Google Platform. The following code snippet allows you to insert the API key.

Program 1: Extract from the Google Maps API key specification program. 
$<$ script async defer

src="https://maps.googleapis.com/maps/api/js?key=AIzaSyCbUYwJrghFMCN5i9n

RKvCPK4BbzcliR_Y" $><$ /script $>$

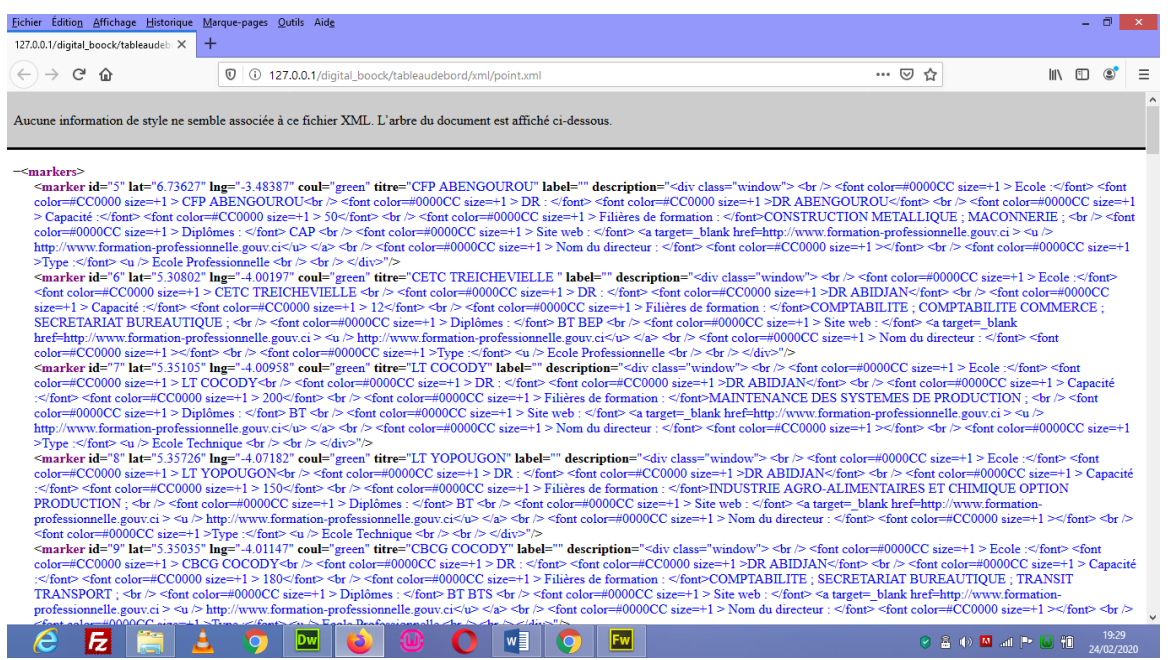

Figure 6. Extract from XML file.

Program 2: Extract from the program for initializing and displaying the Google Maps map.

var lat $=7.60$

var $\operatorname{lng}=-5.0$;

var homeLatlng = new google.maps.LatLng(lat,lng);

var infowindow;

var marker;

var map;

function initialize ()\{

var myOptions $=\{$

center: homeLatlng,

zoom: 7 ,

mapTypeId: google.maps.MapTypeId.roadmap; \};

map = new google.maps.Map (document.getElementById('map-canvas'),myOptions); var

num=markers[i].getAttribute("coul");

var titre=markers[i].getAttribute("titre");

var label=markers[i].getAttribute("label"); marker = createMark-

er(markers[i].getAttribute("description"),latlng,num,titre,label); \} \});\}

function createMarker(description,latlng,num,titre,label ) \{

var marker $=$ new google.maps.Marker $(\{$

position: latlng,

map: map,

icon: \{

url: "http://maps.google.com/mapfiles/ms/icons/"+num+"-dot.png"\},

animation:google.maps.Animation.DROP, draggable:false, title: titre, \});

google.maps.event.addListener(marker,"click",function()\{

if (infowindow) infowindow.close();

infowindow = new google.maps.InfoWindow(\{content: description $\})$;infowindow.open(map, marker);\});return marker;

\} google.maps.event.addDomListener(window, 'load',initialize); 
The Google Maps map is initialized in the JAVSCRIPT program. The "MAP Class" class represents the object that allows loading the Google map on a web page. The creation of an instance of this class is done with the object "new". This requires a default latitude and longitude, but preferably set relative to our study area. In our case, we set the latitude to 7.6 and the longitude to 5.0 to display by default the map which presents the study area which is the Côte d'Ivoire.

We also set the zoom to 7 to properly position the study area. Zooming to 0 corresponds to a map of the entire Earth. The following JAVASCRIPT program is an excerpt from the program which has the role of initializing and displaying the Google Maps map on our web page. The eleventh program line designates the type of card for our display. Note that there are four (4) types of maps with the Google API:

- ROADMAP type maps for a base map in plan mode;

- SATELLITE type maps for a base map in satellite view mode;

- HYBRID type maps for a base map that combines the two previous modes;

- TERRAIN type maps for a basemap in terrain view mode;

- We opt for a display in ROADMAP mode.

The geographic coordinates loaded from the MySQL database and available in the XML file are retrieved through a "latlng" variable. The color of the marker, the title, and the label are retrieved by calling a JAVASCRIPT program. Program 3 is an extract from the JAVASCRIPT program.

A marker description function is used to position the school on the map. This function also allows to give a color to the marker and to display a title which is the name of the school by the property "title". The properties displayed in the description window of the marker are:

- School: give the name of the school;

- DR: the regional management on which the school depends;

- Capacity: the reception capacity of the school;

- Training courses: list of training courses;

- Diplomas: the list of diplomas;

- Website: the school's website;

- Name of the director;

- Type: which indicates whether it is a vocational or technical school.

\section{Results}

\subsection{Map of Technical Education and Vocational Training Schools}

The interactive map of schools brings together all the schools of Technical Education and Vocational Training. Vocational Training schools are identified on the interactive map with green markers and Technical Education schools are displayed with red markers.

This card is available on the platform from the Internet link http://www.educationformation.com/anglais/tableaudebord/ by clicking on the 
"PROF / TECHN" menu. A submenu gives the possibility to display a map exclusively for Vocational training schools or for Technical education schools. The "Home" menu displays a map of all schools without distinction. Figure 7 shows the map of all technical education and vocational training schools. This map reveals that the north-eastern region of Côte d'Ivoire is the region with the lowest concentration in terms of professional and technical school infrastructure. In fact, there is only one school in the whole region, namely the Bondoukou CFP.

\subsection{Map of Schools According to the Number of Educators}

The map of schools according to the number of educators is obtained by selecting the "Educator" option in the "Supervisory staff 1" menu. It is represented by Figure 8. This map concerns a total of fifty-nine (59) schools for which the data has been integrated into our WebSIG.

We recall that the principle according to which the assignments and transfers

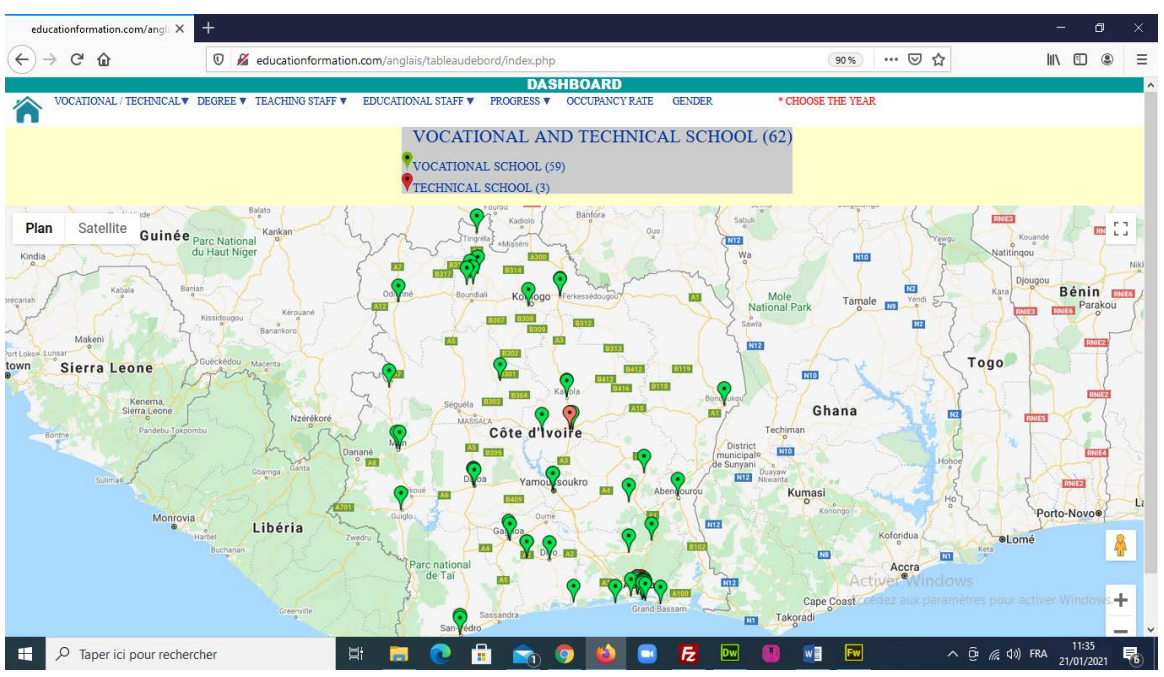

Figure 7. Map of all educational and vocational training schools.

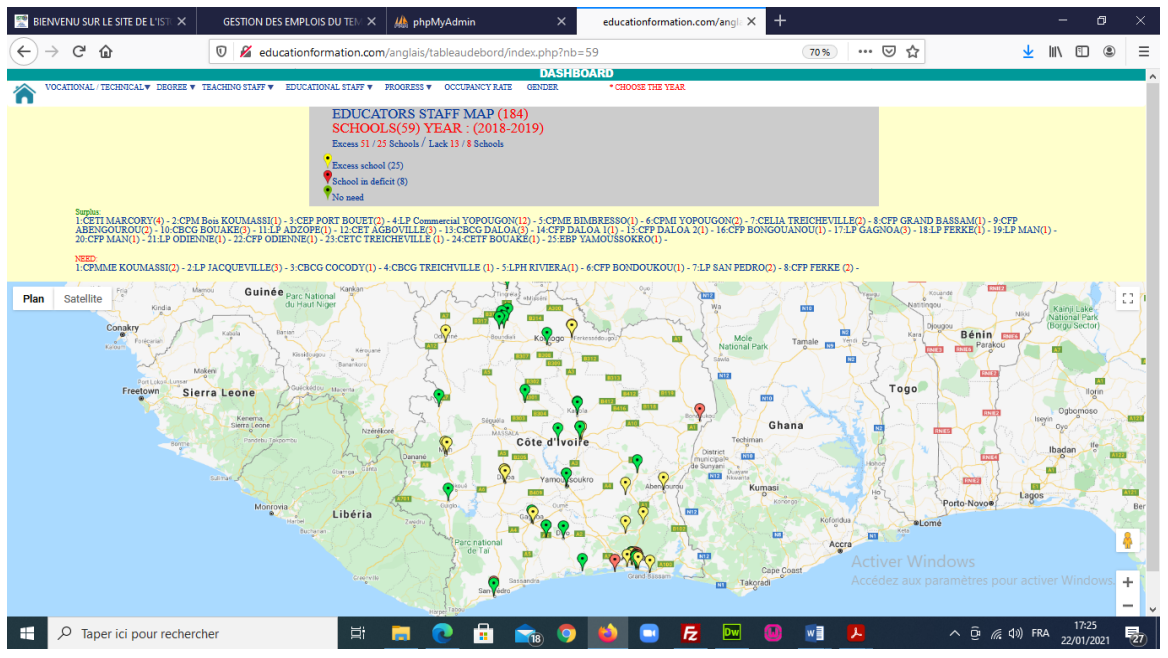

Figure 8. Map of schools according to the number of educators. 
of educators are made is that in a school, we must have one educator for two hundred and eighty (280) students. Knowing the number of schools and the number of educators allows us to know whether the school is in deficit or not.

Schools in deficit are represented by red markers. The ones with a surplus are represented by yellow markers and those with neither deficit nor excess are represented by green markers.

We retain from this map that the distribution of educators is not rationalized according to the number of learners in the schools. Indeed, the map indicates that fifty-one (51) educators are a surplus in twenty-five (25) schools against a need for thirty (13) educators in eleven (11) schools. The distribution of educators is inadequate with the standards set out above. This negatively affects the education of students in schools insofar as the main role of an educator is the supervision and educational support of our learners (Hullebroeck, et al., 2009) [9]. A deficit increases the burden on educators and reduces the quality of supervision of learners.

\subsection{Map of Schools According to the Number of Education Inspectors}

Figure 9 gives us an overview of the map of schools according to the number of education inspectors. It is generated for fifty-nine (59) schools for which the workforce was recorded in our system in 2018-2019.

We count thirty-six (36) education inspectors in the fifty-nine (59) schools. Schools in deficit are marked in red. Schools with a surplus are marked with yellow markers and those with no surplus or deficit are marked with green.

The distribution of educational inspectors in schools normally follows a principle. For seven (7) educators in a school the ministry assigns one (1) education inspector. This corresponds to one inspector for two thousand (2000) students. Knowledge of the school workforce and education inspectors makes it possible

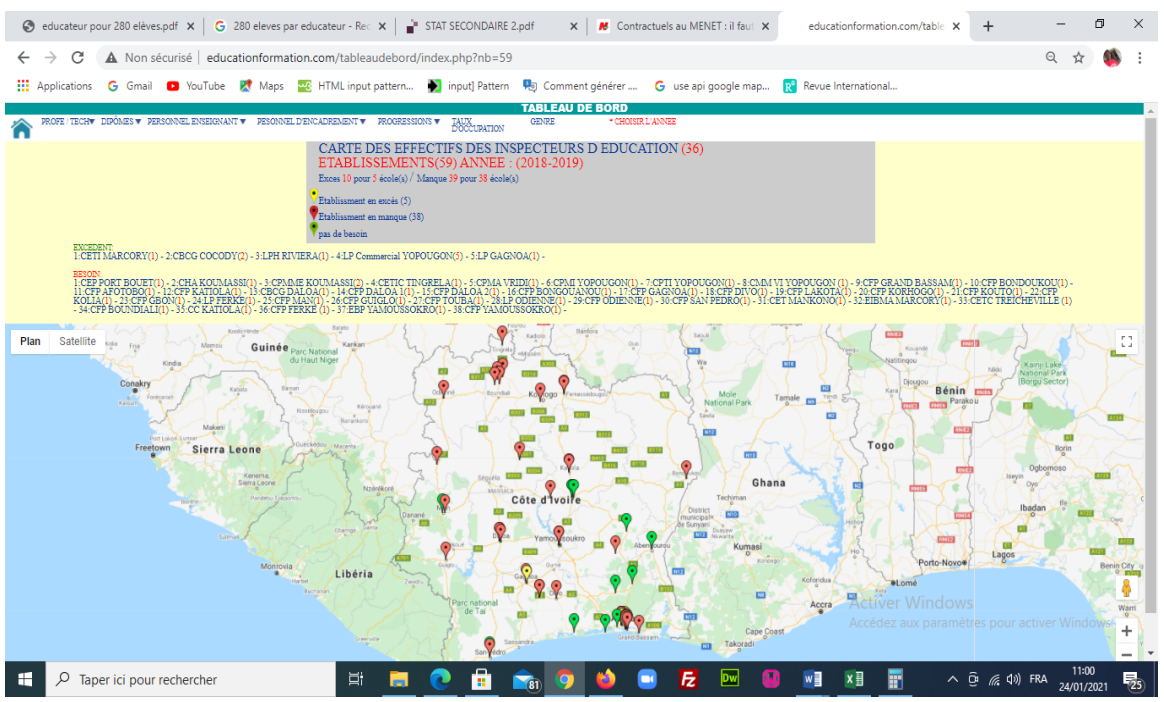

Figure 9. Map according to the number of education inspectors (2018-2019) 
to generate the map of schools according to the number of education inspectors. The report generated on the map reveals that the overall need for these fifty-nine schools is thirty-nine (39) education inspectors. These needs are spread over thirty-eight schools. But five schools have a surplus of nine (9) education inspectors. Those are:

- CETI MARCORY: one (1) education inspector;

- CBCG COCODY: two (2) education inspectors;

- LPH RIVIERA: one (1) education inspector;

- LP Commercial YOPOUGON: four (4) education inspectors;

- LP GAGNOA: (1) education inspector.

The real need is therefore thirty (29) education inspectors for whom a wellfounded request could have been made to the Ministry of the Civil Service.

We note that the majority of the schools that are in need are those in the interior of the country with twenty-seven (27) schools against seven (11) in Abidjan. This is due to the fact that the economic capital of the Côte d'Ivoire remains the most sought after place of affection by agents. In these other loss-making schools, the inspectors present work beyond their normal loads and risk exhaustion according to the study (Tourigny, 2017) [10]. The redeployment of staff to other schools deemed to be in need is a solution.

\section{Discussion}

The WebSIG carried out for vocational training schools made it possible to understand certain important aspects of the training apparatus. The relevance of the results obtained is the consequence of the reliability of the materials used and of the method adopted.

The interactive map of the number of supervisory staff (educators and education inspectors) takes into account the number of staff and the number of school staff for each school. The data made available enabled us to include fifty nine (59) vocational training schools. Our study therefore extends to the entire vocational training system and makes it possible to ascertain the needs for management personnel in real time.

The methodology used is based on the Google Maps API which is a widely used interface for dynamic mapping on the Web. Indeed, appeared in 2004, Google Maps is a free online mapping service. The ability to navigate the world smoothly with a simple internet connection has made this tool a real success. In 2010, the Web had nearly 350,000 sites offering a mapping component using Google Maps technology. The success of this API has been and still is the provision of a free programming interface for developers, allowing them to integrate dynamic mapping into their own websites (Goblet et al, 2010) [11]. We can be comforted in view of the above about the accuracy of our results obtained by this method.

School data reflects, through this study, the disparities in the distribution of education personnel for the year 2018-2019 but also the current disparities insofar as the school populations have not decreased in view of the demographic in- 
crease notified by the works (Koffi, 1990) [3].

\section{Conclusions}

Our work entitled study of the distribution of education and vocational training personnel aims at making an inventory based on the creation of a Geographic Information System on the Internet (WebSIG) on the adequacy between the school numbers of schools and the number of supervisory staff in each school and at the national level in the field of vocational training in Côte d'Ivoire. To achieve this, we first used the MERISE analysis method which allowed us to set up a relational model, secondly HTML5, CSS3, PHP programming languages and JAVASCRIPT, XML and AJAX technology. Software resources, innovative tools for creating dynamic online maps such as Google Maps API, overall school enrollment, school enrollment by school and education staff numbers (educators and education inspectors) have enabled us to achieve the WebSIG and generate the maps.

The interpretation of the results revealed that the education staff is unevenly distributed across all schools and is inadequate with the number of learners. Some schools have a shortage of educational staff while other schools have a surplus. This fact is a factor of exhaustion and a notorious risk for the education and the good supervision of learners intended for the workforce of the Ivorian industry.

\section{Acknowledgments}

The authors send their thanks to the Department of Initial Vocational Training (DFPI) for making the data used in this study available.

\section{Conflicts of Interest}

The authors declare no conflicts of interest regarding the publication of this paper.

\section{References}

[1] UNESCO (2011) L'UNESCO et l'éducation: toute personne a droit à l'éducation. Organisation des Nations Unies pour l'éducation, Paris, 100 p.

[2] INS (2015) Répertoire des localités. Abidjan, Côte d'Ivoire, 47 p.

[3] Koffi, N. (1990) Facteurs de fécondité dans une socité en mutation: le cas de Memni-Montezo. Institut de ddmographie de Paris, Paris, 345 p.

[4] Boutillier J.L. (1971) Croissance démographique et croissance économique en Côte d'Ivoire. Colloque de Démographie Africaine. Cahiers ORSTOM. Série Sciences Humaines, 8, 1-7.

[5] Zah, T. (2015) Impact de la migration sur la démographie en côte d'ivoire. Revue ivoirienne de géographie des savanes, 283-300.

[6] RGPH (2014) Recensement Général de la Population et de l'Habitation (RGPH). Abidjan, Côte d'Ivoire, 49 p. 
[7] UNICEF (2017) Génération 2030 Afrique 2.0. New York, 72 p.

[8] METFP (2016) Réforme de l'enseignement technique et de la formation professionnelle 2016-2025. Abidjan, $107 \mathrm{p}$.

[9] Hullebroeck, P. and Silberberg, V. (2009) Les éducateurs dans l'enseignement secondaire au cœur de l'interaction. Édition Guy Vlaeminck, Bruxelles, 92 p.

[10] Tourigny, M.A. (2017) Besoins de soutien des enseignants du primaire québécois: analyse thématique de leurs perceptions en vue d'offrir des pistes d'amélioration pour quatre aspects de leur pratique professionnelle. Thèse de Doctorat, Université de Sherbrooke, $222 \mathrm{p}$.

[11] Goblet, F., Dirix, M., Goblet, L. and Moreux, J.P. (2010) Développer avec les API Google Maps. Dunod Editions, Paris, 232 p. 